In using ferrocyanide as a reagent for volumetric analysis, it is of the utmost importance to keep all of the conditions absolutely uniform. Provided this is done the results are good, but if there is any variation they are liable to be entirely incorrect.

The following table gives the analytical results in detail :

TABLE.

\begin{tabular}{|c|c|c|c|c|c|c|c|}
\hline \multicolumn{2}{|c|}{ Hydrochloric } & $\begin{array}{l}\text { C } \\
\text { Temper- } \\
\text { ature. }\end{array}$ & $\begin{array}{l}\text { Zinc. } \\
\text { Grams. }\end{array}$ & $\begin{array}{l}\text { Iron. } \\
\text { Grams. }\end{array}$ & $\begin{array}{l}\text { Zinc. } \\
\text { Atoms. }\end{array}$ & $\begin{array}{l}\text { Iron. } \\
\text { A toms. }\end{array}$ & $\begin{array}{l}Z_{\mathrm{nn}}: \mathrm{Fe} \\
\therefore: 100:\end{array}$ \\
\hline $\mathrm{Fe}(\mathrm{CN})_{6}$ & 0 & Cold & 0.01875 & 0.01596 & 287 & 285 & 99 \\
\hline $\mathrm{Fe}(\mathrm{CN})_{6}$ & o & " & 0.04598 & 0.03878 & 702 & 692 & 98 \\
\hline $\mathrm{Zn}$ & 0 & “" & 0.03280 & 0.02866 & $50 \mathrm{I}$ & 5 II & 102 \\
\hline $\mathrm{Zn}$ & o & $"$ & 0.04579 & $0.0383 I$ & 700 & 684 & 98 \\
\hline $\mathrm{Fe}(\mathrm{CN})_{6}$ & 5 & “ & 0.10500 & $0.06_{3} 68$ & 160 & II3 & 70 \\
\hline $\mathrm{Fe}(\mathrm{CN})_{6}$ & 5 & $"(a)$ & 0.42268 & 0.05098 & $3^{18}$ & 227 & $7 \mathrm{I}$ \\
\hline $\mathrm{Fe}(\mathrm{CN})_{6}$ & 0 & Hot & 0.12392 & 0.07616 & I8g & I36 & 72 \\
\hline $\mathrm{Fe}(\mathrm{CN})_{6}$ & 5 & ، & 0.11500 & 0.07575 & I 76 & I35 & 76 \\
\hline $\mathrm{Fe}(\mathrm{CN})_{6}$ & $\frac{1}{7}$ & Cold & 0.11469 & $0.073^{6} 7$ & I 75 & I3 I & 75 \\
\hline $\mathrm{Fe}(\mathrm{CN})_{6}$ & $\frac{1}{7}$ & $"$ & O.II 4 I 4 & 0.07287 & I74 & I30 & 75 \\
\hline Bought as & $\mathrm{Zn}_{2} \mathrm{Fe}$ & $\mathrm{CN} / 6$ & O.I IO 53 & 0.06497 & 169 & II 5 & 78 \\
\hline Bought as & $\mathrm{Zn}_{2} \mathrm{Fe}$ & $(\mathrm{N})_{6}$ & 0.11157 & 0.06508 & 170 & II 6 & 67 \\
\hline & & & $\begin{array}{c}\text { Manganese. } \\
\text { Grams. }\end{array}$ & & $\begin{array}{c}\text { Manganese. } \\
\text { Atoms. }\end{array}$ & & $\begin{array}{c}\mathrm{Mn}: \mathrm{Fe} \\
:: 100:\end{array}$ \\
\hline $\mathrm{Fe}(\mathrm{CN})_{6}$ & 0 & Cold & 0.03050 & 0.03330 & $55^{6}$ & 594 & 107 \\
\hline $\mathrm{Mn}$ & 0 & " & 0.51763 & 0.55500 & $94 \mathbf{I}$ & 991 & IO5 \\
\hline $\mathrm{Fe}(\mathrm{CN})_{6}$ & 5 & “ & 0.08522 & 0.06540 & I55 & II 6 & 75 \\
\hline $\mathrm{Fe}(\mathrm{CN})_{6}$ & 5 & $"(b)$ & 0.03408 & 0.05252 & 309 & 233 & 75 \\
\hline $\mathrm{Fe}(\mathrm{CN})_{6}$ & 5 & Hot & 0.08 I39 & 0.09010 & I 48 & $\mathrm{I} 6 \mathrm{I}$ & 109 \\
\hline $\mathrm{Fe}(\mathrm{CN})_{6}$ & 0 & $" 1$ & $0.0793^{8}$ & 0.07547 & I 44 & I35 & 94 \\
\hline $\mathrm{Fe}(\mathrm{CN})_{6}$ & $\frac{2}{7}$ & Cold & 0.07757 & 0.07844 & $I_{4} I$ & 140 & 99 \\
\hline $\mathrm{Fe}(\mathrm{CN})_{6}$ & $\frac{1}{7}$ & " & 0.07788 & 0.07862 & $\mathrm{I} 42$ & I 40 & 99 \\
\hline
\end{tabular}

[CONTRIBUTION FROM THE ANALYTICAL IABORATORIES OF COLUMBIA UNIVERSITY.]

\title{
ON THE FERROCYANIDES OF ZINC AND MANGANESE.'
}

By EDMUND H. MiLler AxD J. A. Mathews.

Received May 22, 3897.

INTRODUCTION.

$7 \mathrm{HE}$ work to be described was undertaken to determine whether the precipitates formed by adding potassium ferrocyanide to solutions of zinc or manganese are normal ferrocyanides, as given by many authorities, or double potassium ferro-

1 Read at the meeting of the New York Section, May 7,1897 . 
cyanides, as suggested in a preliminary article which appeared in this Journal last December, and also whether the composition of the precipitate is the same if an excess of precipitant be added. The delays encountered in the course of the work made it necessary to confine ourselves to the precipitates formed in the cold, in solutions slightly acidified with hydrochloric acid, as these seemed the most important conditions on account of the solubility of the manganese ferrocyanide in hot solutions, and also on account of the zinc; for if we can establish the composition of the precipitate when formed in the cold to be $\mathrm{K}_{2} \mathrm{Zn}_{\mathrm{s}}$ $\left(\mathrm{Fe}(\mathrm{CN})_{6}\right)_{2}$ we have the results of the standardizing of thousands of ferrocyanide solutions to prove it the same when hot.

Preparation of the Ferrocyanides. - A strong solution of zinc chloride was prepared by dissolving pure granulated zinc in hydrochloric acid, so that but a slight excess of acid remained; this was diluted and placed in two large bottles. To one por. tion potassium ferrocyanide was added so as to leave the zinc in excess. This was thoroughly mixed, and the presence of an excess of zinc chloride confirmed by testing with ferric chloride. The precipitate was white, flocculent, and showed at first a tendency to settle. It was washed by decantation with water seven times, the clear supernatant liquid being removed by a siphon and the precipitate thoroughly agitated with the water added. After the seventh washing no chlorides were present. The precipitate was then transferred to a filter, washed again, and then dried at $95^{\circ} \mathrm{C}$. (Sample $A$.)

To the second portion an excess of potassium ferrocyanide was added and the solutions thoroughly mixed. An excess of ferrocyanide was found to be present by testing with ferric chloride. The precipitate was white, flocculent, and settled well at first, but after washing settled more slowly. It was washed six times, as already described, except that after several washings alcohol was added with the water to hasten the settling of the precipitate. This aided somewhat, but the process is not rapid, as the washing of this precipitate required eight weeks. After the sixth washing the liquid gave no test for ferrocyanide. It was not found possible to filter this zinc ferrocyanide, so it was left in the bottle and samples taken direct for the determination of the ratio of zinc to iron. (Sample B.) 
Manganese ferrocyanides were prepared as follows: To a concentrated aqueous solution of manganous chloride, acidified with hydrochloric acid, potassium ferrocyanide was added so as to leave the manganese in excess. The precipitate was greenish white and flocculent, but settled slowly. It was washed with water several times, as already described. At first the precipitate ran through the filter paper, but on standing for several weeks it became more flocculent and filtered well. After filtering it was dried in an air-bath below $100^{\circ} \mathrm{C}$. This ferrocyanide, when dried, has a slate color. (Sample C.)

Another portion of manganous chloride was mixed with an excess of ferrocyanide solution and allowed to stand. The precipitate scarcely settled at all, so after waiting several weeks and making several incomplete decantations, alcohol was added with the water which effected a more rapid separation. It was washed seven times; the last wash water was free from ferrocyanide, but contained a trace of chloride. The washing of this precipitate required many weeks. (Sample D.) This sample was not dried but kept for the determination of ratios only. On boiling a portion of this ferrocyanide it became dark blue and more flocculent, evidently undergoing decomposition. The hydrochloric acid present in each case was about one cc. of 1.20 sp. gr. The temperature was $23^{\circ} \mathrm{C}$.

These ferrocyanides have a most remarkable affinity for water. Attempts were made to determine the water present in Sample $C$ by drying it in an air-bath. Eleven weighings were made at intervals of from one to two hours, at increasing temperatures from $102^{\circ} \mathrm{C}$. to $150^{\circ} \mathrm{C}$, , but no constant weight was reached. On cooling, water was again absorbed. The avidity for moisture is so great that the tube containing the precipitate, though tightly corked, was found to steadily increase in weight. When water is added to these ferrocyanides, dried at $100^{\circ} \mathrm{C}$., it is taken up with a crackling sound and a marked evolution of heat.

To avoid error from the absorption of moisture the following method was adopted: The tube containing the sample dried at $100^{\circ} \mathrm{C}$. was weighed, then a portion shaken out into a platinum boat and the tube recorked, allowed to assume a constant weight, and reweighed. The boat containing the sample was imme- 
diately placed in a glass tube in a combustion furnace, heated in a current of dry air till the sample began to char; and the water absorbed by calcium chloride. While this determination was in progress five or six portions for analysis were weighed out into small beakers by difference, then another portion was weighed into a boat as before and the moisture again determined. The average of the two percentages of moisture was user in calculating the intermediate portions to the dry basis. The percentages so obtained never varied more than one-quarter of a per cent.

Sample A.-Zinc chloride in excess contained: water $9.4 \mathrm{I}$ and 9.33 per cent., average used 9.37 per cent.

Sample C.-Manganous chloride in excess contained: water 3.35 and 3 . I per cent, average 3.23 per cent. Other determinations made after redrying at $100^{\circ} \mathrm{C}$, after an interval of about one month, gave water 3.50 and 3.32 per cent., average $3.4 \mathrm{I}$ per cent., showing that the sample when dried at $100^{\circ} \mathrm{C}$. has a nearly constant amount of water.

Wyrouboff ${ }^{\prime}$ assigns to the manganese ferrocyanide four molecules of water, corresponding to 2.28 per cent. We have found that, when dried from $145^{\circ}$ to $148^{\circ} \mathrm{C}$, from 2.26 to 2.36 per cent. loss in weight results, but do not believe the compound contained any definite water of crystallization. He gives to the zinc ferrocyanide twelve molecules of water, or 13.40 per cent. This result we have not confirmed.

We do not believe any further evidence is necessary to prove that these ferrocyanides are without water of crystallization.

Methods of Decomposition.-The ignition method given by Wyrouboff was tried in connection with the determination of potash, but the results were found to be low and irregular as the resulting oxides adhered to the platinum and the potash could not be leached out completely.

Rose's method for the determination of cyanogen, as given by Fresenius, was tried on the zine ferrocyanide but without satisfactory results. Three portions were digested with silver nitrate, adding a few drops of nitric acid from time to time, and the resulting silver cyanide weighed on balanced filters. The percentages of cyanogen were: $44.63,44.83$, and 44.12 , which

1 Ann. phys. Chem. (5), 8, 474, 485. 
agreed well with the calculated percentages of $\mathrm{Zn}_{8} \mathrm{~K}_{2}\left(\mathrm{Fe}(\mathrm{CN})_{6}\right)_{2}$, which is 44.70 , but it was found that the iron in the filtrate was invariably low and that when the precipitate of silver cyanide was scorified with test lead and cupelled, the silver resulting corresponded to only about 35 per cent. of cyanogen, showing an incomplete decomposition of the ferrocyanide.

Decomposition by means of concentrated sulphuric acid was tried with satisfactory results, except for the separation of small quantities of carbon, which had a tendency to climb up the sides of the casserole.

The method finally adopted, and which we consider entirely satisfactory, is as follows: Add to the casserole containing about one gram of the ferrocyanide, ten to fifteen cc. of concentrated nitric acid, and heat till the action is over and no more nitrous fumes are seen; cool, rinse down the sides of the casserole with water, add about twenty cc. of concentrated sulphuric acid, and boil, holding the casserole over the flame and, keeping the contents constantly in motion, until copious fumes of sulphuric acid are evolved, cool, and again rinse down the sides. At this point a decided blue color usually appears as some of the ferrocyanide which adheres to the sides of the vessel escapes decomposition; add more sulphuric acid and repeat the operation till nearly all of the sulphuric acid has been driven off ; cool, dilute again, and, if no blue color appears, add a few drops of hydrochloric acid to dissolve the ferric sulphate and the solution is ready for analysis. The addition of nitric acid prevents any separation of carbon. In spite of these precautions, however, we have sometimes found traces of iron in the ferrous condition which required subsequent oxidation.

\section{ANALYSIS OF THE ZINC FERROCYANIDES.}

Sample $A$.-Zinc chloride in excess. Determination of zinc and iron. 0.9322 gram of the precipitate dried at $100^{\circ} \mathrm{C}$. was decomposed, as already described; the iron was precipitated as basic acetate, washed, then the precipitate dissolved in hydrochloric acid and twice precipitated by ammonia. The precipitate of ferric hydroxide was dissolved in hydrochloric acid, reduced by stannous chloride, and titrated by potassium permanganate according to the Zimmerman-Reinhart method. The filtrates containing zinc were combined, acidified with acetic acid, and 
the zinc precipitated as sulphide in a hot solution. The zinc sulphide, after washing, was dissolved in nitric acid, a decided excess of a saturated solution of microcosmic salt added, the solution boiled and then neutralized with ammonia, and allowed to stand on a water-bath till only a trace of ammonia remained; when cold the zinc ammonium phosphate was filtered and weighed on balanced papers after drying at $100^{\circ} \mathrm{C}$. The results were: iron I6.II per cent., zinc 27.93 per cent. A duplicate determination of iron gave 16.07 per cent.

The zinc was also determined by decomposing the ferrocyanide by potassium hydroxide, then precipitating by hydrogen sulphide, and finally, as zinc ammonium sulphate. The method gave 27.60 per cent. of zinc.

For the determination of potassium 0.5360 gram was decomposed as usual, the iron precipitated by ammonia, then the zinc by hydrogen sulphide, the filtrate acidified with sulphuric acid, and evaporated to dryness and ignited in a platinum dish. The potassium sulphate weighed O.I 208 gram, corresponding to II.I4 per cent. of potash when calculated to the dry basis.

Sample B.-Ferrocyanide in excess. On account of the diffculty of filtering and because the presence of potassium is already proved, only the ratio of iron to zinc was determined in this case. Portions, judged to contain about one gram of the dry compound, were transferred to casseroles as before and the alcohol driven off on the water-bath. The sample was then decomposed as usual and the zinc determined as already described. The iron was weighed as $\mathrm{Fe}_{2} \mathrm{O}_{3}$. The results were as follows :

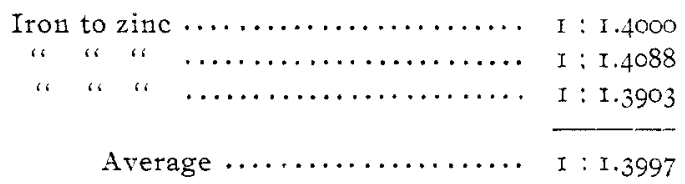

The following table shows a comparison of our results with the theory calculated for $\mathrm{Zn}_{3} \mathrm{~K}_{2}\left(\mathrm{Fe}(\mathrm{CN})_{6}\right)_{2}$ and with the analytical results of Wyrouboff. The percentages of cyanogen are calculated from the iron: 


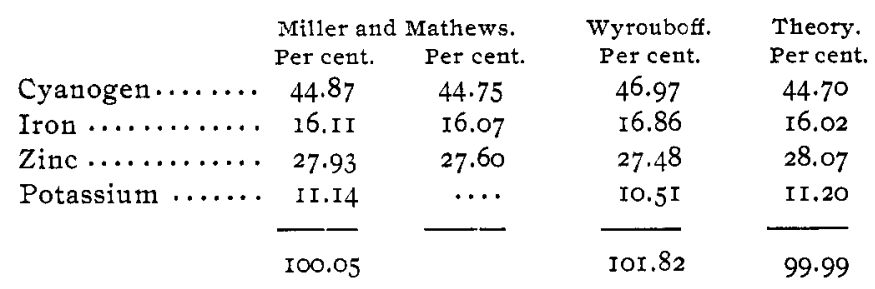

Our results agree very closely with the theory and agree perfectly with the results obtained by titration when uranium acetate is used as an indicator. The ratio of iron to zinc is $I: I .49$, compared to the theory I : I.500, while Wyrouboff's is I : I.395. This ratio coincides almost exactly with the proportions we found when the ferrocyanide was in excess (Sample $B$ ), and shows that Wyrouboff came to the conclusion that the precipitate was the same whichever was in excess on account of the inaccuracy of his analytical results.

The ratios obtained from Sample $B$, ferrocyanide in excess, correspond to a formula containing 5 iron and 7 zinc, which would be $\mathrm{Zn}_{7} \mathrm{~K}_{6}\left(\mathrm{Fe}(\mathrm{CN})_{8}\right)_{8}$.

\section{COMPARISON OF RESULTS.}

Theory, iron to zinc ............. I : I.4000

Miller and Mathews, iron to zinc .... I : I.3997

Wyrouboff, iron to zinc........... I : $\mathrm{x} .3955$

\section{ANALYSIS OF THE MANGANESE FERROCYANIDE.}

Sample C.-Manganous chloride in excess. Portions of about one gram each were decomposed by nitric and sulphuric acids, in the same way as the zinc ferrocyanide, then dissolved in hydrochloric acid and water, as before. The manganese and iron were determined in the same portion as follows: The iron was precipitated twice as basic acetate, then by ammonia, and weighed as $\mathrm{Fe}_{2} \mathrm{O}_{8}$. The filtrates and washings from the two basic acetate precipitations were combined, concentrated, and the manganese precipitated by bromine after adding sodium acetate, etc. ; the oxide of manganese, $\mathrm{MnO}_{2}$, was dissolved in hydrochloric and sulphurous acids, and precipitated as manganese ammonium phosphate in the ordinary manner. The manganese was ignited and weighed as pyrophosphate.

The method used for the determination of potassium was the 
same as described under zinc except that the manganese was precipitated in an ammoniacal, not an acetic acid solution.

The results calculated to the dry basis are as follows: Iron I6.36 and 16.40 per cent., manganese 17.67 and 17.67 per cent., potassium 20.33 and 19.64 per cent.

Other determinations of manganese and iron in the same por. tion gave the following ratios:

Fe: Mn : : I : I.I039, and as I : I.I080.

Sample D.-Ferrocyanide in excess. On account of the perverse character of this precipitate only the ratio of iron to manganese was determined. The method of decomposition and analysis has already been described. The results are as follows :

$$
\begin{aligned}
& \text { Fe:Mn : : I : } 1.0502 \\
& \text { Fe:Mn : : I : } 1.0623 \\
& \text { Fe:Mn : : I : } 1.075^{8}
\end{aligned}
$$

The following table gives a comparison of our results with the theory calculated from Wyrouboff's formula without the water

\begin{tabular}{|c|c|c|c|c|}
\hline & \multicolumn{2}{|c|}{ Miller and Mathews. } & \multirow{2}{*}{$\begin{array}{l}\text { Wyrouboff. } \\
\text { Per cent. }\end{array}$} & \multirow{2}{*}{$\begin{array}{l}\text { Theory. } \\
\text { Per cent. }\end{array}$} \\
\hline & Per cent. & Per cent. & & \\
\hline Cyanogen ........ & 45.57 & 45.68 & 45.44 & $45 \cdot 5^{2}$ \\
\hline Iron $\ldots . . . . .$. & 16.36 & 16.40 & I6.3I & 16.34 \\
\hline Manganese........ & 17.67 & 17.67 & I8. I9 & I 7.89 \\
\hline \multirow[t]{2}{*}{ Potassium........ } & 20.33 & $\ldots$ & 19.35 & 20.23 \\
\hline & 99.93 & & 99.29 & $99 \cdot 98$ \\
\hline
\end{tabular}
of crystallization, ${ }_{5} \mathrm{Mn}_{8} \mathrm{Fe}(\mathrm{CN})_{6},{ }_{4} \mathrm{~K}_{4} \mathrm{Fe}(\mathrm{CN})_{6}$ and with his own results. The cyanogen is calculated from the iron:

These results agree very fairly with the theory for Wyrouboff's formula, but still better with a ratio of ro iron to I I manganese, as will be seen from the following ratios:

$$
\begin{aligned}
& \text { Fe : Mn : : I : I.099 } \\
& \text { Fe : Mn : : I : } 1.097 \\
& \text { Fe: } \mathrm{Mn}:: \mathrm{I}: \mathrm{I} .104 \\
& \text { Fe: Mn : : I : I.108 } \\
& \text { Average I : I.IO2 }
\end{aligned}
$$

Theory for Io Fe : I I Mn, I : I. I00

While these results agree most perfectly with a ratio of to to 
I I, we do not wish to advance a corresponding formula, as the difference between this ratio and the 9 to ro of Wyrouboff is very slight and the composition of the precipitate very readily affected by slight changes in the conditions of precipitation. The average of three ratios of iron to manganese determined on Sample $D$, ferrocyanide in excess, is $\mathrm{I}: \mathrm{r} .0628$, corresponding to a formula containing i 6 iron to 7 manganese. We do not give to this ratio its appropriate formula, as the precipitate may be a mixture of two simple ferrocyanides, but we believe that a comparison of these ratios shows that the manganese precipitate does not have the same composition whether manganese or ferrocyanide is in excess, as stated by Wyrouboff.

The physical properties of this precipitate confirm the fact that it readily undergoes a change in composition, for if a solution of potassium ferrocyanide is poured into one of manganous chloride it first is pinkish white, on adding more ferrocyanide it becomes greenish, and when the ferrocyanide is in excess a light slate color.

The conclusions arrived at by us are:

First.-The precipitates formed by potassium ferrocyanide and chloride of zinc or manganese are double ferrocyanides and not normal ferrocyanides, as given by Prescott and Johnson ${ }^{1}$ and by Stone. ${ }^{2}$

Second.-The ferrocyanides formed when the metal is in excess does not contain water of crystallization, as given by Wyrouboff. ${ }^{3}$

Third.-The precipitate formed in a dilute hydrochloric acid solution of zinc chloride by potassium ferrocyanide when the zinc chloride is in excess, is $\mathrm{Zn}_{8} \mathrm{~K}_{2}\left(\mathrm{Fe}(\mathrm{CN})_{8}\right)_{2}$ as given by Wyrouboff. ${ }^{3}$

The precipitate is not the same whichever is in excess. When ferrocyanide is in excess the ratio of iron to zinc is as I to I.4O, which corresponds to $\mathrm{Zn}_{7} \mathrm{~K}_{8}\left(\mathrm{Fe}(\mathrm{CN})_{6}\right)_{5}$.

Fourth.-The manganese precipitate formed when manganese chloride is in excess agrees well with the formula ${ }_{5} \mathrm{Mn}_{2} \mathrm{Fe}(\mathrm{CN})_{6}$, ${ }_{4} \mathrm{~K}_{4} \mathrm{Fe}(\mathrm{CN})_{6}$, as given by $\mathrm{W} y$ rouboff, but better with a ratio of Io iron to I I manganese. When the ferrocyanide is in excess the

1 Qual. Anal., pp. 57 and 67.

2 This Journal, 17, 473.

8 Am. Chim. Phys. (5), 8, 474, 485 . 
composition is different, corresponding to a ratio of I6 iron to I 7 manganese. The manganese precipitate is very readily affected by changes in the conditions of precipitation.

In regard to the bearing of these results on the methods in use for the titration of zinc and manganese by potassium ferrocyanide, we believe the accuracy of the ordinary method of titrating zinc in a dilute hydrochloric acid to be confirmed and that the following reaction takes place:

$$
2 \mathrm{~K}_{4} \mathrm{Fe}(\mathrm{CN})_{6}+{ }_{3} \mathrm{ZnCl}_{2}=\mathrm{Zn}_{3} \mathrm{~K}_{2}\left(\mathrm{Fe}(\mathrm{CN})_{6}\right)_{2}+6 \mathrm{KCl}
$$

The difference in the composition of the precipitate when ferrocyanide is in excess explains why all attempts to add an excess of ferrocyanide and titrate back by permanganate have failed.

The complicated and variable character of the manganese precipitate constitutes a serious objection to the method of determining manganese by potassium ferrocyanide, for aside from the difficulties arising from the solubility of the manganous ferrocyanide and its consequent action on indicators, the titration must be conducted under very carefully regulated conditions to give satisfactory results.

DISCUSSION ON THIS AND THE PRECEDING PAPER.'

Mr. Miller: All of these ferrocyanides can be resolved into two ferrocyanides having simple ratios, as follows:

$Z$ inc in excess :

$$
\mathrm{Zn}_{3} \mathrm{~K}_{2}\left(\mathrm{Fe}(\mathrm{CN})_{6}\right)_{2}=\mathrm{ZnK}_{2} \mathrm{Fe}(\mathrm{CN})_{6}+\mathrm{Zn}_{2} \mathrm{Fe}(\mathrm{CN})_{6} .
$$

$\mathrm{K}_{4} \mathrm{Fe}(\mathrm{CN})_{6}$ in excess :

$$
\mathrm{Zn}_{7} \mathrm{~K}_{6}\left(\mathrm{Fe}(\mathrm{CN})_{6}\right)_{5}={ }_{3} \mathrm{ZnK}_{2} \mathrm{Fe}(\mathrm{CN})_{6}+2 \mathrm{Zn}_{2} \mathrm{Fe}(\mathrm{CN})_{6} .
$$

Manganese in excess:

Ratio of II Mn to Io $\mathrm{Fe}=9 \mathrm{MnK}_{2} \mathrm{Fe}(\mathrm{CN})_{8}+\mathrm{Mn}_{2} \mathrm{Fe}(\mathrm{CN})_{6}$.

$\mathrm{K}_{4} \mathrm{Fe}(\mathrm{CN})_{6}$ in excess :

Ratio of $\mathrm{I}_{7} \mathrm{Mn}$ to $\mathrm{I}_{6 \mathrm{Fe}}=\mathrm{I}_{5} \mathrm{MnK}_{2} \mathrm{Fe}(\mathrm{CN})_{8}+\mathrm{Mn}_{2} \mathrm{Fe}(\mathrm{CN})_{6}$.

The explanation may be as follows: The acid in solution $(\mathrm{HCl})$ reacting on the potassium ferrocyanide gives free hydro-

1 Note By THE EDTTOR. -The Publication Committee have decided to publish the discussion on this and the preceding paper inasmuch as it seems to throw some additional light upon the subject. Hereafter such discussions, if published, will appear in the Proceedings. 
ferrocyanic acid, which precipitates the normal ferrocyanide, ${ }^{1}$ liberating in turn free acid, which continues the reaction. In this way a little acid can effect a great change in the composition of the precipitate.

If this theory is correct in a neutral solution, $\mathrm{ZnK} \mathrm{K}_{2} \mathrm{Fe}(\mathrm{CN})$, and $\mathrm{MnK}_{2} \mathrm{Fe}(\mathrm{CN})_{6}$ should be formed, while the proportions of zinc or manganese to potassium ferrocyanide remaining the same the greater the quantity of acid the more of the normal ferrocyanide $\mathrm{R}_{2} \mathrm{Fe}(\mathrm{CN})_{8}$ should be formed. This may be complicated, however, by the solubility of the manganese compound.

Expressed briefly, as the acid increases, the manganese or zinc in the ratio increases, and as the ferrocyanide increases, the zinc or manganese in the ratio diminishes.

This view of the composition and conditions for formation of these precipitates has received most important confirmation from the work of Stone and Van Ingen, for as I had expected they have found the two salts, $\mathrm{K}_{2} \mathrm{MnFe}(\mathrm{CN})_{6}$ and $\mathrm{K}_{2} \mathrm{ZnFe}(\mathrm{CN})_{6}$, to be formed in a cold neutral solution. The compound $\mathrm{K}_{4} \mathrm{Mn}_{4}\left(\mathrm{Fe}(\mathrm{CN})_{6}\right)_{8}$ and $\mathrm{K}_{4} \mathrm{Zn}_{4}\left(\mathrm{Fe}(\mathrm{CN})_{6}\right)_{3}$ also agree with this theory, for they may be resolved into $\mathrm{R}_{2} \mathrm{Fe}(\mathrm{CN})_{8} .2 \mathrm{~K}_{2} \mathrm{RFe}(\mathrm{CN})_{6}$ and are formed in an exceedingly dilute acid solution and occupy a position intermediate between the $\mathrm{K}_{2} \mathrm{ZnFe}(\mathrm{CN})_{6}$ of the neutral solution, and the $\mathrm{Zn}_{3} \mathrm{Fe}(\mathrm{CN})_{6} \cdot \mathrm{K}_{2} \mathrm{ZnFe}(\mathrm{CN})_{6}$ obtained when more hydrochloric acid is present.

It must be admitted that these precipitates are extremely sensitive to changes of condition, but we have in uranitum acetate an indicator which in an acid solution shows with certainty $\mathrm{Zn}_{3} \mathrm{~K}_{2} \mathrm{Fe}(\mathrm{CN})_{6}$, and according to Stone and Van Ingen we have in dilute cobalt nitrate an indicator which turns at $\mathrm{K}_{4} \mathrm{R}_{4}\left(\mathrm{Fe}(\mathrm{CN})_{6}\right)_{3}$.

$M r$. Van Ingen: I know that in carrying out the work of Mr. Stone, in obtaining a precipitate for analysis, there were two or three cases in which decomposition took place, and we had a ferrocyanide of iron formed, not shown by the strong blue color in the precipitate.

Another matter: a very curious changing in color took place during the washing of the manganese precipitate where we had manganese in excess and not where we had ferrocyanide in excess. It would start out sometimes with dark purple, from dark purple

1 Wyrouboff: Ann. phys. Chem. (5), 8, 474. 
to a dark pink, and gradually washing out until we ended with a pale slate color, and the solubility made it very hard to know just when we got through, because the cobalt tests would show ferrocyanide to the rery end. All the precipitates were washed in bulk of $6,700 \mathrm{cc}$, allowed to settle in bottles, then siphoned off as far as possible, and water added. Most of them had from twenty to thirty washings, and by adding barium chloride we were enabled to get four or five washings a day. Before doing that, we were well satisfied with one washing in two days. As you continue, the washing and settlings get slower and slower, but there seems to be some very curious change in the manganese salts during this washing. The precipitate changed color in parts entirely during the washing.

Mr. Hiller: There is a difference in color where the manganese or ferrocyanide is in excess and you get changes in color going from one washing to another.

Mr. Van Ingen: I was referring to washing the precipitate where manganese was in excess. We started with pinkish purple and ended up with a slate color.

Mr. Miller: I don't remember seeing a purple color, but I noticed a change from pinkish to sort of slate color.

[CONTRIBUTION FROM THE CHEMICAI LABORATORY OF THE UNIVERSITY OF Michigar.]

\section{HALIDES AND PERHALIDES OF PYRIDINE. ${ }^{1}$}

By P. F. TKowbridge AND O. C. DIEHL,

Received May 21, I897.

ACTION OF BROMINE UPON IODIDES OF PYRIDINE.

Pyridine Hydriodide Dibromide, $\mathrm{C}_{5} \mathrm{H}_{6} \mathrm{~N} . \mathrm{HI} . \mathrm{Br}_{2}$, or $\mathrm{C}_{5} \mathrm{H}_{5} \mathrm{~N}$. $\mathrm{HBr}$.IBr.-Reddish-brown, thin laminae or large, prismatic plates. Melting-point $172^{\circ}-175^{\circ} \mathrm{C}$. Very soluble in alcohol, with difficulty in chloroform, and scarcely at all in water. The samples for analysis were crystallized from alcohol.

Pure pyridine hydriodide was dissolved in water and brom. inated by passing carbon dioxide through bromine and then throttgh the solution. At first a very dark red precipitate formed which appeared to be nearly pure iodine. Upon continued bromination the precipitate became brownish yellow,

1 Continuation of previous paper. This Journa1, 19, 322 . 